\title{
Feasibility of Environmentally Sustainable Buildings in State of Qatar
}

\author{
Ahmed Gomaa \\ Department of Environmental Engineering, University of Alexandria, Egypt
}

Copyright $\bigcirc 2016$ by authors, all rights reserved. Authors agree that this article remains permanently open access under the terms of the Creative Commons Attribution License 4.0 International License

\begin{abstract}
The world has witnessed incalculable technological achievements, population growth and corresponding increases in resource use since the Industrial Revolution; the side effects of those activities were recognized as we entered the new century. As world population continues to expand, implementation of resource-efficient measures in all areas of human activity is imperative. The purpose of this research is to examine the history of Sustainable Building, main factors and categories. Various Green Building rating systems, their components, scoring system and main categories were discussed and a comparison between LEED "Leadership in Energy and Environmental Design" rating system and QSAS "Qatar Sustainable Assessment System" was conducted. The research also examined the feasibility of environmentally sustainable buildings throughout evaluating the cost savings related to main components (Construction, life time and environmental) costs. The prime rule for this research is to discuss Environmental impacts, mitigation measures and cost implications of using green building in Gulf Area using Qatar as a model throughout examining QSAS "Qatar Sustainable Assessment system" and highlighting weather sustainable building techniques provide a real contribution to the Society, Environment and Economy or not. It was found that, there are financial benefits of Green Building include lower energy, waste, and water costs, lower environmental and emissions costs, lower operation and maintenance costs and savings from increased productivity and health are highly effective in Gulf Area. In addition, some improvements were recommended for the rating system used in the study.
\end{abstract}

Keywords Green Building, QSAS, Sustainability Pillars, Feasibility

\section{Introduction}

Constructing Green Buildings cost-effectively requires integrated Green Building design and a careful commissioning process. The commonly higher initial cost of
Green design and construction can be expected to drop as designers and builders gain experience in building green. The financial benefits of Green Buildings of Energy, Waste and Water savings and emissions reductions should be viewed as precise, reasonably conservative estimates of direct benefits that alone significantly exceed the marginal cost of Green Building. Health and productivity benefits may be viewed as reasonable, conservative estimates within a large range of uncertainty.

\subsection{Objective}

The objective of this paper is to motivate all projects stakeholder to turn Greener throughout highlighting the value gained by energy and water reductions. In addition, to address these benefits to Official Decision Makers in order to encourage them to financially support certified Green building owners to improve their sustainable performance.

\subsection{Literature Review}

Alameda County Waste Management authority \& Source reduction and recycle board (2004) put Green Building Guidelines, which summarizes three convergences of fundamental objectives as follows:

1- Natural resource conservation

2- Energy efficiency

3- Indoor air quality

California Building Standards commission (2010) implemented a green building standard code; the purpose of this code is to improve public health, safety and general welfare by enhancing the design and construction of building using building concepts having a reduced negative impact or positive environmental impact and encouraging sustainable construction practices in the following categories:

1- Planning and design

2- Energy efficiency

3- Water efficiency and conservation

4- Material conservation and resource efficiency

5- Environmental quality

Galayda and yudelson (2010) discussed five steps for 
establishing a corporate sustainability program for an organization. Those five steps were:

1. Setting the vision, by outlining how and in what dimension the challenge of sustainability might create a comparative advantage for the organization

2. Staffing the effort, by assign the taskforce to oversee the effort. Successful taskforce should include people from different divisions and expertise.

3. Establish metrics to measure progress, it is important to measure environmental impacts to measure progress and improvement.

4. Implementing strategic initiatives, by generating initiatives that are practically relevant to each business during planning stage and do all the efforts to implement them

5. Communicating the results to all stakeholders, by effectively communicating sustainability efforts to all internal and external stakeholders. Sustainability reports could be used as an effective tool to communicate results.

They concluded that, crafting a sustainability vision and properly staffing the effort allows a foundation to establish applicable metrics, initiatives and goals. Progress toward meeting these goals must be communicated internally to keep the momentum going.

Todd litman (2011) put recommendations for improving LEED transportation and Parking credits, when he proposed to that, LEED credits should encourage development in accessible, multi-model locations, use of alternative modes and reduced vehicles trip generation; and more efficient parking management which could approximately double energy conservation and emission reduction impact.

Greg Kats (2003) discussed the cost and financial benefits of Green Building and concluded that, including lower energy, waste, and water costs, lower environmental and emissions costs, lower operations and maintenance costs, and savings from increased productivity and health. These benefits range from being predictable (energy, waste and water savings) to relatively uncertain (productivity and health benefits). Energy and water savings can be predicted with reasonable precision, measured, and monitored over time. In contrast, productivity and health gains are less precisely understood and far harder to predict with accuracy.

Environmental Protection Agency in association with Environmental Assessment Board (2000) developed guidelines for preparing Environmental Management Plans as a part of Environmental Impact Assessment to serve as a feasible and cost effective measures that may reduce potential significant adverse environmental impacts to acceptable levels. They summarized the Environmental Management Plan involvement areas as flowing:

1- Environmental policy of the establishment

2- Specific objective of the plan

3- Identification and description of the potential adverse impacts and environmental risks associated with implementation of the proposed/existing project.

4- Detailed description of the appropriate mitigation and compensatory measures together with design, equipment description and operational procedure to respond to these impacts or to avoid or reduce risks

5- Determination of requirements for ensuring that responses to predicted impacts are made effectively and an implementation schedule (timing) for mitigation measures that must be carried out as part of the project.

6- Development of a program to monitor the impacts arising out of the project operational activities and the effectiveness of the proposed mitigation measures. The monitoring plan should detail as a minimum, impact indicators, location and frequency of sampling, analytical methods to be used and criteria for evaluation. This program should also include regular audits of the implementation of the Environmental Management Plan.

7- Identification of persons within the establishment responsible for executing the Environmental Management Plan.

8- Identification of necessary funds (including budget) to implement mitigation measures.

9- Emergency response plan in case where the project uses or produces substances known to have a deleterious effect on the environment.

The United Nation (2001) provided guidelines for a comprehensive process throughout an environmental and social impact assessment of road projects; they introduced two new concepts for enhancing the effectiveness of Environmental Impact Assessment. The first adoption was to replace the term (Environmental Impact Assessment EIA) by the term (Environmental and Social Impact Assessment ESIA) so it could convey the message that equal emphasis should be placed on the natural as well as the human environments in the ESIA process. The report has provided sufficient evidence that ignoring the impacts on the human environment would lead to grave consequences that affect a large population base over an extended period.

The guideline also introduced another concept; it was the multistage framework for implementing the ESIA process. The analysis had shown that the multistage ESIA framework offered a workable mechanism to intimately incorporate the process of ESIA analysis. Adhering to the multistage ESIA framework will ensure that the ESIA will begin during the very early stage of the project-planning phase, thereby minimizing the chances of major planning "errors" in respect of the preservation of the natural and human environments. By following through the multistage ESIA process, one is also assured of continuity of ESIA implementation right to the post-construction evaluation and monitoring stage of project development.

The stages provided by the study were:

1- Environmental and Social screening

2- Initial Environmental and Social examination

3- Environmental and Social impact analysis

4- Monitoring of Environmental and social measures during project construction

5- Post-Construction Environmental and Social evaluation 
The study advised a two-step familiarization program to be implemented, the first step of the program should be involving the decision makers and planners it would serve as a familiarization session to gather comments and feedbacks and to seek endorsement on proposed concepts.

The second step would involve country-level workshops targeting professionals and officers of prospective ESIA executing and authorizing agencies.

The U.S. department of Commerce, National Oceanic and Atmospheric Administration and National Marine Fisheries Service formed an integrated committee on (1994) to study the social impact assessment predicted on a nation. They concluded that decision makers should understand the consequences of their decisions before they act, and that the people affected will not only be appraised of the effects, but have the opportunity to participate in designing their future. The report explained the reasons why the social environment is different from the natural environment because it reacts in anticipation of change, but can adapt in reasoned ways to changing circumstances in part of the planning process. In addition, persons in different social settings interpret change in different ways and react in different ways. Because of this complexity, or the political consequences of making explicit the social consequences of projects and programs, social impact assessment has not been well-integrated into agency decision making.

Environmental Impact Assessment (EIA) was first introduced in the USA under the Environmental Policy Act (1969). Since then it has evolved and a variety of offshoot assessment techniques have emerged (focusing on social, biodiversity, environmental health and cumulative effects and risk) acting as a broader impact assessment toolkit.

The International Institute for Environment and Development (IIED) (2009) briefed the stages of an Environmental Impact Assessment process, which includes Screening, alternatives, preliminary assessment, scoping, mitigation, main EIA study and environmental impact statement, review. Monitoring, highlighting that, EIA intention is to identify the impacts (both beneficial and adverse) of a proposed public and private development activity and help decision-makers at every stage of the project planning cycle.

\section{Green Building process and Qatar's National Vision 2030}

Sustainability is fulfilling the requirements of Environment, Economy and Society to create and maintain the conditions nature and human with all related activities can positively contribute to each other. Qatar National Vision 2030 added a fourth pillar, which is "Human Development" to the above to act as an umbrella containing the other three pillars.

\section{Qatar Green Building Rating System}

The development of the rating system took advantage of a comprehensive review of combined best practices employed by a mix of established international and regional rating systems. This review has been performed while taking into consideration the needs that are specific to Qatar's local environment, culture, and policies. This has led to adaptations and additions to sustainability criteria. Measurements for the rating system are designed to be performance-based and quantifiable. The result is a performance-based sustainable building rating system customized to the unique conditions and requirements of the State of Qatar.

According to QSAS certification is granted based on:

\section{Level 1 (Design)}

The design certification assesses the project's design deliverables from design stage up to post- construction stage. Project shall receive a Letter of Conformance (LOC) upon Approval of Resubmission indicating the achieved QSAS star rating of the completed design documents that are ready for construction.

\section{Level 2 (Construction)}

The assessor evaluates the aspects of Construction process perform measurements related to normative standards and accepted practices, and consider what impacts the project can mitigate.

\section{Level 3 (Operation)}

The assessor verifies original design intent, evaluates changes made through renovation or additions and considers what impacts the project can mitigate.

QSAS certification levels as following:

Table 1. QSAS Certification Levels

\begin{tabular}{|c|c|c|}
\hline Score & Certification level & QSAS certification \\
\hline$X<0$ & - & Certification denied \\
\hline $0.0 \leq X \leq 0.5$ & $*$ & \multirow{2}{*}{ Certification achieved } \\
\hline $0.5 \leq X \leq 1.0$ & $* *$ & \multirow{2}{*}{} \\
\hline $1.0 \leq X \leq 1.5$ & $* * *$ & \\
\hline $1.5 \leq X \leq 2.0$ & $* * * *$ & \\
\hline $2.0 \leq X \leq 2.5$ & $* * * * *$ & \\
\hline $2.5 \leq X \leq 3.0$ & $* * * * * *$ & \\
\hline
\end{tabular}

The assessment system consists of eight categories and 48 criteria; the following table summarizes the categories, their associated weights and the goal of each category

Category

Urban conductivity (UC)

Site (S)

$$
\begin{gathered}
\text { Weight } \\
8 \% \\
9 \%
\end{gathered}
$$



Energy (E)
Water (W)
Materials (M)
Indoor environment (IE)
Culture and economic value $\mathrm{CE}$ )
Management and operation (MO)
$24 \%$
$16 \%$
$8 \%$
$14 \%$
$13 \%$
$8 \%$

The assessment system consists of 8 categories and 48 criteria. Categories and associated goal of each category are summarized as follows:

Urban conductivity (UC)

Factors associated with the urban environment such as zoning, transportation networks and loading, traffic congestion, pollution and waste water/sewage infrastructure.

Table 2. Urban Connectivity Min \& Max Score

\begin{tabular}{|c|c|c|c|c|}
\hline No. & Criteria & $\begin{array}{c}\text { Min. } \\
\text { Score }\end{array}$ & $\begin{array}{c}\text { Max. } \\
\text { Score }\end{array}$ & Weight \\
\hline UC.1 & $\begin{array}{c}\text { Load on Local traffic } \\
\text { condition }\end{array}$ & 0 & 3 & $1.80 \%$ \\
\hline UC.2 & Pedestrian Pathways & -1 & 3 & $1.08 \%$ \\
\hline UC.3 & Proximity to Amenities & -1 & 3 & $0.69 \%$ \\
\hline UC.4 & Light Pollution & -1 & 3 & $0.58 \%$ \\
\hline UC.5 & Noise Pollution & -1 & 3 & $0.43 \%$ \\
\hline UC.6 & Public Transportation & -1 & 3 & $1.30 \%$ \\
\hline UC.7 & Private Transportation & -1 & 3 & $0.39 \%$ \\
\hline UC.8 & $\begin{array}{c}\text { Sewer \& Waterway } \\
\text { Contamination }\end{array}$ & -1 & 3 & $1.08 \%$ \\
\hline UC.9 & $\begin{array}{c}\text { Shading of adjacent } \\
\text { properties }\end{array}$ & -1 & 3 & $0.65 \%$ \\
\hline & Total Possible & -8 & 27 & $8.00 \%$ \\
\hline
\end{tabular}

Site (S)

Factors associated with land use such as land conservation or remediation and site selection, planning and development.

Table 3. Site (S) Min. \& Max. Score

\begin{tabular}{|c|c|c|c|c|}
\hline No. & Criteria & $\begin{array}{l}\text { Min. } \\
\text { Score }\end{array}$ & $\begin{array}{l}\text { Max. } \\
\text { Score }\end{array}$ & Weight \\
\hline S.1 & $\begin{array}{c}\text { Ecological value of } \\
\text { land }\end{array}$ & -1 & 3 & $2.59 \%$ \\
\hline S.2 & $\begin{array}{l}\text { Vegetation and } \\
\text { shading }\end{array}$ & -1 & 3 & $1.17 \%$ \\
\hline S.3 & Desertification & -1 & 3 & $1.94 \%$ \\
\hline S. 4 & Rainwater Runoff & -1 & 3 & $1.29 \%$ \\
\hline S.6 & Heat Island Effect & -1 & 3 & $0.65 \%$ \\
\hline S.7 & $\begin{array}{l}\text { Adverse Wind } \\
\text { Conditions }\end{array}$ & -1 & 3 & $0.97 \%$ \\
\hline S. 8 & Acoustic Condition & -1 & 3 & $0.39 \%$ \\
\hline \multicolumn{2}{|r|}{ Total Possible } & -7 & 21 & $9.00 \%$ \\
\hline
\end{tabular}

\section{Energy (E)}

Factors associated with energy demand of buildings, the efficiency of energy delivered and the use of fossil energy sources that result in harmful emissions and pollution.

Table 4. Energy (E) Min. \& Max. Score

\begin{tabular}{|c|c|c|c|c|}
\hline No. & Criteria & $\begin{array}{c}\text { Min } \\
\text { Score }\end{array}$ & $\begin{array}{c}\text { Max. } \\
\text { Score }\end{array}$ & Weight \\
\hline E.1 & $\begin{array}{c}\text { Energy Demand } \\
\text { Performance }\end{array}$ & -1 & 3 & $5.20 \%$ \\
\hline E.2 & $\begin{array}{c}\text { Energy Delivery } \\
\text { Performance }\end{array}$ & -1 & 3 & $5.20 \%$ \\
\hline E.3 & Fossil Fuel depletion & -1 & 3 & $3.64 \%$ \\
\hline E.4 & $\mathrm{CO}_{2}$ Emissions & -1 & 3 & $4.55 \%$ \\
\hline E.5 & $\mathrm{NO}_{\mathrm{x}}$, So $_{\mathrm{x}}$ \& Particular & -1 & 3 & $5.41 \%$ \\
\hline \multicolumn{2}{|c}{ Matter } & -5 & 15 & $24.00 \%$ \\
\hline
\end{tabular}

Water (W)

Factors associated with water consumption and its associated burden on municipal supply and treatment systems.

Table 5. Water (W) Min. \& Max. Score

\begin{tabular}{|c|c|c|c|c|}
\hline No. & Criteria & Min Score & $\begin{array}{c}\text { Max. } \\
\text { Score }\end{array}$ & Weight \\
\hline W.1 & Water consumption & -1 & 3 & $16.00 \%$ \\
\hline \multicolumn{2}{|c|}{ Total possible } & -1 & 3 & $16.00 \%$ \\
\hline
\end{tabular}

Materials (M)

Factors associated with material extraction, processing, manufacturing, distribution, use/reuse and disposal.

Table 6. Material (M) Min. \& Max. Score

\begin{tabular}{|c|c|c|c|c|}
\hline No. & Criteria & $\begin{array}{c}\text { Min } \\
\text { Score }\end{array}$ & $\begin{array}{c}\text { Max. } \\
\text { Score }\end{array}$ & Weight \\
\hline M.1 & Regional Materials & -1 & 3 & $1.85 \%$ \\
\hline M.2 & $\begin{array}{c}\text { Responsible sourcing of } \\
\text { materials }\end{array}$ & N/A & N/A & N/A \\
\hline M.3 & Structure Reuse: On-site & -1 & 3 & $0.91 \%$ \\
\hline M.4 & Material Reuse: Off-site & -1 & 3 & $1.54 \%$ \\
\hline M.5 & $\begin{array}{c}\text { Recycled Materials } \\
\text { M.6 }\end{array}$ & -1 & 3 & $1.85 \%$ \\
\hline Design for Disassembly & -1 & 3 & $1.85 \%$ \\
\hline & Life Cycle Assessment & N/A & N/A & N/A \\
\hline
\end{tabular}

Indoor environment (IE)

Factors associated with indoor environment quality such as thermal comfort, air quality, acoustic quality and light quality. 
Table 7. Indoor Environment (IE) Min. \& Max. Score

\begin{tabular}{|c|c|c|c|c|}
\hline No. & Criteria & $\begin{array}{c}\text { Min. } \\
\text { Score }\end{array}$ & $\begin{array}{c}\text { Max. } \\
\text { Score }\end{array}$ & Weight \\
\hline IE.1 & Thermal Comfort & -1 & 3 & $1.20 \%$ \\
\hline IE.2 & Low-Emitting Materials & -1 & 3 & $1.60 \%$ \\
\hline IE.3 & Natural Ventilation & -1 & 3 & $1.60 \%$ \\
\hline IE.4 & Mechanical Ventilation & -1 & 3 & $1.60 \%$ \\
\hline IE.5 & Indoor Chemical \& & -1 & 3 & $1.60 \%$ \\
\hline IE.6 & Vollutant Source Control & -1 & 3 & $1.20 \%$ \\
\hline IE.7 & Glare Control & -1 & 3 & $1.20 \%$ \\
\hline IE.8 & Illumination Levels & -1 & 3 & $1.20 \%$ \\
\hline IE.9 & Acoustic Quality & -1 & 3 & $1.20 \%$ \\
\hline IE.10 & Daylight & -1 & 3 & $1.60 \%$ \\
\hline & Total Possible & -10 & 30 & $14.00 \%$ \\
\hline
\end{tabular}

Culture and economic value $\mathrm{CE}$ )

Factors associated with cultural conservation and support of the local economy

Table 8. Culture and economic value (CE) Min.\&Max. Score

\begin{tabular}{|l|l|c|c|c|}
\hline No. & Criteria & $\begin{array}{l}\text { Min. } \\
\text { Score }\end{array}$ & $\begin{array}{l}\text { Max. } \\
\text { Score }\end{array}$ & Weight \\
\hline CE.1 & $\begin{array}{l}\text { Heritage and Cultural } \\
\text { Identity }\end{array}$ & -1 & 3 & $8.67 \%$ \\
\hline CE.2 & $\begin{array}{l}\text { Support of National } \\
\text { Economy }\end{array}$ & -1 & 3 & $4.33 \%$ \\
\hline \multicolumn{2}{|l|}{ Total Possible } & $\mathbf{- 2}$ & $\mathbf{6}$ & $\mathbf{1 3 . 0 0 \%}$ \\
\hline
\end{tabular}

Management and operation (MO)

Factors associated with building design management and operation.

Table 9. Management and operation (MO) Min.\& Max. Score

\begin{tabular}{|c|c|c|c|c|}
\hline No. & Criteria & $\begin{array}{l}\text { Min. } \\
\text { Score }\end{array}$ & $\begin{array}{l}\text { Max. } \\
\text { Score }\end{array}$ & Weight \\
\hline MO.1 & Commissioning Plan & 0 & 3 & $2.67 \%$ \\
\hline MO.2 & Energy Use Sub-metering & 0 & 3 & $0.89 \%$ \\
\hline MO.3 & Leak Detection & 0 & 3 & $1.77 \%$ \\
\hline MO.4 & $\begin{array}{c}\text { Organic Waste } \\
\text { Management }\end{array}$ & N/A & N/A & N/A \\
\hline MO.5 & Recycling Management & N/A & N/A & N/A \\
\hline MO.6 & $\begin{array}{l}\text { Intelligent Building } \\
\text { Control System }\end{array}$ & -1 & 3 & $2.67 \%$ \\
\hline \multicolumn{2}{|r|}{ Total Possible } & -1 & 12 & $8.00 \%$ \\
\hline
\end{tabular}

\section{Comparison between QSAS and Other Systems}

Two comparisons were conducted between QSAS and LEED as one of the most commonly rating systems used around the world. In addition, a comparison between QSAS and ESIDAMA the rating system used in the same region.
The purpose of this comparison is to highlight and identify how close the QSAS from International systems and how effective would be if the whole Gulf region is covered by similar sustainability rating systems.

\subsection{Comparison between LEED and QSAS}

The Leadership in Energy and Environmental design (LEED) green building rating system program is a national consensus-based, market-driven building rating system designed to accelerate the development and implementation of green building practices. In short, it is a leading-edge system for designing, constructing and certifying the world's greenest and best buildings.

LEED works well because it is simple to understand, it is divided into five categories related to sitting, water conservation, energy, materials and indoor environmental quality, plus an innovation and design category.

\section{LEED}

LEED is a point system. There are 100 base points, 6 possible Innovation in design and 4 Regional Priority points

If a building has scored well under LEED, it is likely that it well score well under QSAS.

LEED is strong in Occupant comfort \& internal pollution issues. It also covers some ground not found in QSAS like Tobacco Smoke Control.

LEED now has a requirement for the USGBC to have access to whole-building Energy and Water usage data.

\section{QSAS}

QSAS is a weighing scoring system. Each category and criterion has an associated weight based on its relative environmental, social, and economic impact.

Achieving a positive sore according to QSAS is easy

QSAS is giving designers more freedom to meet the required standards using their discretion and there is less of tick box mentality.

QSAS is strong on pedestrian and cyclist spaces. It is also stronger than LEED in acoustics.

QSAS is giving more care to cultural, Economic and heritage values as a category to sustained and preserved while LEED is not paying the same attention to such requirement.

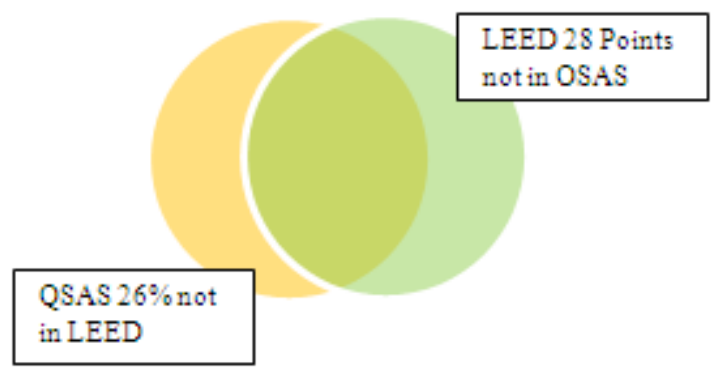

Figure 1. Comparison between LEED and QSAS

Figure (1) shows that there are a similarity in almost $75 \%$ 
of the requirements represented in Water efficiency, material and Indoor environmental quality.

LEED showed differences in giving more score to Innovation, Regional priority and Energy, which contributes almost 18 points. Another 10 points are recorded to the use of alternative fuel vehicles and vegetated roofs in sustainable sites and products made from plant that are harvested within a 10 years cycle and forests use of materials.

QSAS showed significant difference in giving a weight to Culture and economic value $13 \%$ and Management and operation $8 \%$. Another $5 \%$ are recorded in the Water category for the use of low flow water fixtures.

\subsection{Comparison between ESTIDAMA and QSAS}

ESTIDAMA, which means "Sustainability" in Arabic, aims to create more sustainable communities, cities and global enterprises. Pearl rating system is organized into seven categories that are fundamental to more sustainable development. These categories are:

-Integrated development process (IDP)

- Natural system (NS)

- Livable buildings (LB)

- Precious water (PW)

- Resourceful energy (RE)

- Stewarding materials (SM)

- Innovating practices (IP)

Within each section, there are both mandatory and optional credits and credit points are awarded for each optional credit achieved.

\section{ESTIDAMA}

Pearl has three stages of rating. The first stage is during the design and construction and Operational rating is only awarded after 2 years of at least $80 \%$ occupancy.

Development codes for the city of Abu Dhabi are currently integrating ESTIDAMA's goals and Pearls requirements into them.

ESTIDAMA is a point-based system. Points are added up to a final rating, which ranges from One Pearl to Five Pearls.

\section{QSAS}

Certification is granted based on three level, Design, Construction and Operation.

QSAS system reference existing national codes and planning guides such as Qatar Construction specifications (QCS)

QSAS is a weighing scoring system. Once a score is determined project receives a certification level from one to six stars.

QSAS contained ESTIDAMA's requirements and furthermore has $13 \%$, which are the requirements of Culture and Economic values.

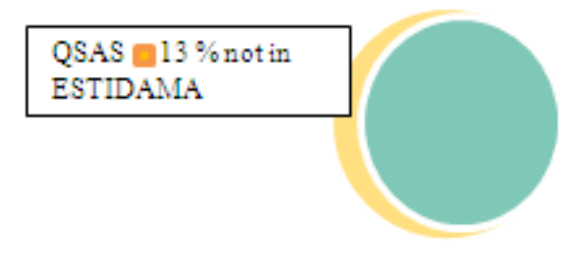

Figure 2. Comparison between ESTIDAMA and QSAS

Figure (2) shows all ESTIDAMA requirements are adopted in QSAS the only difference that QSAS has the requirement of Culture and economic value $13 \%$.

The above shows that utilizing the requirements of QSAS and ESTIDAMA could be used as a foundation for developing any Green Building Rating system in the Gulf Region considering the similarity of conditions such as weather conditions, people's culture and values, lack of water and the value of natural resources.

\subsection{Application of Sustainability rating systems in Gulf Region}

Sustainability is now a top priority in Gulf region, countries like Qatar developed QSAS, which the name was recently modified to Global Sustainability Assessment Systems (GSAS) to suit the use of other neighboring countries and Unite Arab Emirates developed ESTIDAMA Building Rating System, Design \& Construction Version in 2010. There are some trial to develop Green Building Rating systems in some other countries like Lebanon and Egypt.

\section{Environmental Impacts, Mitigation Measures and Cost Implications Analysis}

The core target of the research is to analyze the feasibility of sustainable buildings in the State of Qatar, Gulf Area. QSAS was examined as a model for the study. Every criterion was examined throughout its components; cost impact analysis was conducted to each item. The study focused on medium sized mixed use buildings. The study did not cover projects related solely to Oil and Gas production and refining such as pipe line projects, well heads and / or refineries. Administrational and semi domestic buildings were considered in the study.

Surveillance for 50 projects were conducted to identify expected budgets for major components of those studied buildings, those components required budgets were for design, Civil and Architectural works, Mechanical works, Electrical and Instrumentation activities and expected management and operation costs.

Results obtained were summarized in the following table. 
Table 10. Expected Budgets for project's major components

\begin{tabular}{|c|c|c|}
\hline \multirow{2}{*}{ Number of projects } & \multicolumn{2}{|c|}{$\mathbf{5 0}$} \\
\cline { 2 - 3 } & Range & Average \\
\hline Civil and Architectural works & $34 \%-48 \%$ & $41 \%$ \\
\hline Mechanical works & $9 \%-22 \%$ & $16 \%$ \\
\hline $\begin{array}{c}\text { Electrical and Instrumentation } \\
\text { works }\end{array}$ & $10 \%-34 \%$ & $22 \%$ \\
\hline Commissioning & $5 \%-9 \%$ & $7 \%$ \\
\hline management and operation & $9 \%-20 \%$ & $14 \%$ \\
\hline
\end{tabular}

The surveillance also showed that the percentage between Materials to labor costs is approximately 60\%: 40\%.

The concluded cost implications depend on the following assumptions:

Project cost is the cost calculated by Asset Holder or Facility Owner, which will be developed after this as Contract Project Value, estimations of contractor or subcontractors are not considered

Some of the estimated costs were based on local market prices in the state of Qatar which may slightly vary from a country to another due to the availability of services and / or the proximity of construction materials.

Utilizing QSAS requirements the environmental categories as topical sections discussions of green Building criteria, ways to improve their implementation, and cost implications was examined and the results were as follows:

Urban Connectivity (UC)

No to low additional costs

The assumption of having a clear project charter and Project Scope of Work (SOW) will minimize any extra effort from the design office. Cost of design as per the local prices would be varying from $3.0 \%$ to $5.0 \%$ of the project total budget. The assumption of having a clear project charter and Project Scope of Work (SOW) will minimize any extra effort from the design office; however, the extra measures implemented in the project design aspect would be varying from $4.0 \%$ to $6.0 \%$ (difference will be $1.0 \%$ more if any).

Site (S)

No to low additional costs

Most of the requirements soft/hard landscaping will be implemented under all circumstances, giving more attention to the designs would easily achieve Green Building record. Some benefits would be achieved also throughout the mixed use of the building, which considered being economical gain.

However, some costs would be added due to the use of solar reflective material; overall project / facility cost will be influenced slightly by the cost of solar reflective material.

\section{Energy (E)}

Medium to high Additional cost for labor and materials.

Possible additional cost (rage from medium to high) for labor and materials, especially all recommended thermal improvement strategies, also minor added costs for additional sensors / switches/ controls/ wiring. Costs will be added also due to initial training for maintenance crows.

Effective training programs for project team can reduce and contain labor costs, and savings will be reached by reduced operating costs and energy savings over a reasonable amount of time.

\section{Water (W)}

Additional cost for labor and materials.

Cost could be reduced by providing training for operating staff and over the project lifetime due to low consumptions.

\section{Materials (M)}

No to very low additional cost.

Additional cost (if any) for material verification, tests and inspections.

\section{Indoor Environment (IE)}

Low to medium additional costs. Most of the requirements depend on the value for special kinds of materials and design.

\section{Culture and Economical Value (CE)}

No additional cost.

Economical gains are expected.

Management and Operation (MO)

Low additional cost for labor and materials.

Low additional costs for labor and materials varying upon the complexity of the systems mechanisms used.

\section{Results and Discussion}

Environmentally friendly buildings allow owners and occupants to save money. This would be achieved by reducing Energy use, Electrical consumptions, and landfill waste and water consumption. According to QSAS requirements, an improvement should be sensed throughout reduction in energy and electrical use within $20 \%$ to $40 \%$ while excellent performance would be achieved if reduction were more than 40\%. (QSAS Energy (E) Requirements gives a positive score to $20 \%$ to $40 \%$ Energy Demand Savings and Fossil Fuel conservation).

Water consumption reduction would be acceptable within 10\%: 50\% (QSAS Water (W) Requirements gives a positive score to $10 \%$ to $50 \%$ water consumption saving).

Implementing Green Building practices also raises the value of the property this would be achieved by Improving Indoor Air Quality, Conserve and restore Natural Resources, Enhance asset value and profit and optimum utilization for material used. QSAS encourage the use of recycled/reused materials, score would be granted if improvement were ranging from 5\% to $20 \%$ (QSAS material (M) Requirements gives a positive score to $5 \%$ to $20 \%$ for the use of recycled materials).

The growth and development of communities has a large impact on Society and economics. A major benefit of Building Green in Gulf area is the reduction of Carbon 
Dioxide emissions which according the QSAS score would be granted if emissions were reduced from $20 \%$ to $40 \%$ QSAS Energy (E) Requirements gives a positive score to $20 \%$ to $40 \%$ reduction in $\mathrm{CO}_{2}$ Emissions.

Unmeasured benefit to Green Building is the optimization of life-cycle economic performance; these long-term benefits need to have an improved template to assess and evaluate the income gained through using and implementing.

Green Building feasibility is subject to achieving a reasonable score in the four main criteria of the QSAS, which are (Energy, Water, Indoor Environment and Culture and Economical Value). These four elements represent approximately $65 \%$ of the score and contribute $50 \%$ of water and energy consumptions

It is not necessary for a Green Building Certified Facility to be environmentally friendly. Certification, according to QSAS, could be achieved with any positive score and this score would be influenced by many construction technologies such as safety requirements, which improve the score of Noise Pollution, Adverse Wind Condition and Acoustic Condition.

In addition, Commissioning is a systematic process of ensuring that all new building systems perform and interact according to original design documents and the owner's intentions in the meantime, presence of commissioning plan would increase the value scored throughout QSAS rating system despite the fact that, commercial Green Buildings are recommended to be commissioned.

For example, an Equitable Building (Achieved score in Economy and Society factors) would be treated as a certified Green Building which in the same time is not an Environmental friendly Building. This means that, a Green Building must have a reasonable score out of the sustainability three pillars (Environment, Economy and Society) to earn an environmentally friendly record.

\section{Conclusions}

The financial benefits of Green Buildings of Energy, Waste and Water savings and emissions reductions should be viewed as fairly precise, reasonably conservative estimates of direct benefits that alone significantly exceed the marginal cost of Green Building. Health and productivity benefits may be viewed as reasonable, conservative estimates within a large range of uncertainty

Constructing Green Buildings cost-effectively requires integrated Green Building design and a careful commissioning process. The commonly higher initial cost of Green design and construction can be expected to drop as designers and builders gain experience in building green.

According to the QSAS certification is denied for a score less than $(0)$ and could be achieved for any score above this number, which could be easily granted even if the project is not adding any value to the community throughout the three main sustainability pillars. Additional classifications could be imposed to the QSAS scoring system in order to motivate projects' stakeholders to achieve a higher rating within the established system.

Modifications proposed for the QSAS rating system could be summarizes as following:

Table 11. QSAS Proposed Modified Certification Levels

\begin{tabular}{|c|c|c|c|}
\hline Score & $\begin{array}{c}\text { Certification } \\
\text { level }\end{array}$ & $\begin{array}{c}\text { QSAS } \\
\text { certification }\end{array}$ & $\begin{array}{c}\text { Proposed } \\
\text { modifications }\end{array}$ \\
\hline $\mathrm{X}<0$ & - & $\begin{array}{c}\text { Certification } \\
\text { denied }\end{array}$ & $\begin{array}{c}\text { Certification } \\
\text { denied }\end{array}$ \\
\hline $0.0 \leq \mathrm{X} \leq 0.5$ & $*$ & & Fair \\
\cline { 1 - 1 } $0.5 \leq \mathrm{X} \leq 1.0$ & $* *$ & \multirow{3}{*}{$\begin{array}{c}\text { Certification } \\
\text { achieved }\end{array}$} & Good \\
\cline { 1 - 1 } $1.0 \leq \mathrm{X} \leq 1.5$ & $* * *$ & & Excellent \\
\hline $1.5 \leq \mathrm{X} \leq 2.0$ & $* * * *$ & & \\
\hline $2.0 \leq \mathrm{X} \leq 2.5$ & $* * * * *$ & & \\
\hline $2.5 \leq \mathrm{X} \leq 3.0$ & $* * * * * *$ & &
\end{tabular}

The proposed modification could have a direct reflect on the financial aids provided from the state of Qatar to facilities and Insurance fees required from the facility, by this concept this aid and insurance could be categorized according to the level of complying with QSAS certification level

\section{Acknowledgements}

I acknowledge this research to the ancient Egyptians who built in the early age of civilization their Sustainable Green Buildings. For those who designed, built and managed pyramids, temples, palaces, and house and river Nile controlling structures. To Imhotep the first architect, engineer and physician in early history and the one who invented the method of a stone-dressed building. I acknowledge this research also to Hassan Fathy the Egyptian architect who pioneered appropriate technology for building for the poor, especially by working to re-establish the use of mud brick and Laurence Wilfred "Laurie" Baker who initiated cost-effective energy-efficient architecture and unique space utilization and simple but beautiful aesthetic sensibility.

I also like to acknowledge this thesis to Dr. Ahmed Awad "Qatar Petroleum Environmental specialist" for his unlimited support and valuable help.

I would like to acknowledge this thesis to every one appreciate the gift given from almighty God called "Mother earth" and is welling to sustain it.

\section{REFERENCES}

[1] "Multifamily Green Building Guidelines" The Alameda County Waste Management authority \& Source reduction and recycle board (2004)

[2] "California Green Building Standard Code" California Building Standards commission (2010)

[3] "Corporate sustainability management best practices" Galayda 
and yudelson 2010

[4] "Recommendations for improving LEED transportation and Parking credits" Todd litman (2011)

[5] "Life is our ultimate customer: Lean to sustainability" Gary Langenwalter (2006)

[6] "High performance buildings - LEED and Energy Star" Colorado Springs utilities (2008)

[7] "The cost and financial benefits of Green Building" Greg Kats, Capital E (2003)

[8] "Building rating systems (certification programs) a comparison of key programs" Air Quality Sciences (2009)

[9] "A technical Manual for Material Choices in Sustainable Construction" Integrated Waste Management Board California Environmental Protection Agency (2000)
[10] "Green building guidelines for the rehabilitation of historic and non-historic buildings" the Presidio Trust (2002)

[11] "Environmental Protection Agency / Environmental Assessment Board" Environmental Impact Assessment Guideline Volume 3 mining (2000)

[12] "Multistage Environmental and Social Impact Assessment of road projects - Guidelines for a comprehensive process" United Nations (2001)

[13] "Guidelines and Principles for Social Impact Assessment" Inter-organizational committee on guidelines and principles for social assessment (1994)

[14] "Guidance on EIA Screening" Office for official publications of the European Communities (2001)

[15] Pearl Building Rating Systems "Design and Construction" Version 1.0 (2010) 